\title{
Monitoring of thermophysical properties of wooden buildings envelopes in climatic conditions of Murmansk and Petrozavodsk
}

\author{
Svetlana Buryachenko ${ }^{1}$, Zahar Voronin ${ }^{2}$, Iana Karachentseva ${ }^{1, *}$, Alexander Kuzmenkov ${ }^{2}$, \\ and Oksana Popova ${ }^{1}$
}

${ }^{1}$ Murmansk State Technical University, Murmansk, Russia

${ }^{2}$ Petrozavodsk State University, Petrozavodsk, Russia

\begin{abstract}
The article presents a program of a planned scientific experiment on a comprehensive study of the energy efficiency of the enclosing structures of a wooden low-rise building. The main focus of the study is on the construction of the wooden walls. Experimental buildings implemented in two constructive and technological solutions in different climatic conditions (climatic regions of the Republic of Karelia and the Murmansk region) are considered as objects of research. The review of normative methods of field studies of thermophysical properties of enclosing structures is carried out. An experimental research method is proposed by means of a system for monitoring temperature and humidity parameters, developed and installed in the layers of heterogeneous structures. As a result, a program of an experiment for a comprehensive study in a stationary mode of the internal microclimate of a building was formed.
\end{abstract}

\section{Introduction}

At present, the individual housing construction sector is actively developing in the Russian Federation. According to the Federal State Statistics Service, in recent years, for the territories under consideration, the proportion of individual housing construction in the total housing construction is: for the Republic of Karelia - 45\%, and for the Murmansk region - 90\%. Many city dwellers of blocks of flats are interested in buying suburban real estate or land for the construction of an individual residential building. The development of individual construction is also programs for the allocation of land plots, subsidies and concessional lending when purchasing an individual residential building.

Special attention is paid to low-rise wooden construction. In the North-West regions of Russia, wood has historically been one of the main materials for construction, and there is a wealth of experience in the construction of wooden houses. Currently, wooden low-rise housing construction is supported by the state and arouses additional interest among the population.

\footnotetext{
* Corresponding author: karachentsevayam@mstu.edu.ru
} 
Despite the considerable experience in the construction and operation of wooden buildings in the USA, Canada and in the Scandinavian countries, foreign scientists continue to study various aspects of wooden buildings [1-5]. Various aspects of low-rise wooden housing construction are also being actively studied in Russia [6-9]. For consumers, the results of such studies will be useful when choosing technical decisions when purchasing or making a decision about construction. For material, structure and product manufacturers, such research simplifies the search for competitive advantages of products in the market.

This article presents a planned program for a number of research experiments aimed at studying the issues of assessing the impact of constructive solutions for the walls of lowrise wooden buildings on the heat-shielding characteristics and parameters of the internal microclimate of a building. The main data are the data obtained in the field conditions of operation of objects in the climatic conditions of two regions (Murmansk region and the Republic of Karelia). The greatest attention in the study is paid to the enclosing structures of the walls. The main purpose of the study is to assess the heat-shielding characteristics of the building envelope, taking into account the given design solutions and real operating conditions [10-11].

\section{Materials and Methods}

\subsection{Model (experimental) buildings}

Two identical objects, built in 2020 on the territories of Murmansk and Petrozavodsk, will be used as an experimental base for the study. The experimental objects are wooden onestory buildings, implemented in two constructive and technological solutions: one part of each building is made using frame technology, the other part - using the technology of a double frame made of rounded logs. The buildings are one-storey, rectangular in plan dimensions 12x5 $\mathrm{m}$ with a pitched roof [12-14] (Figure 1).
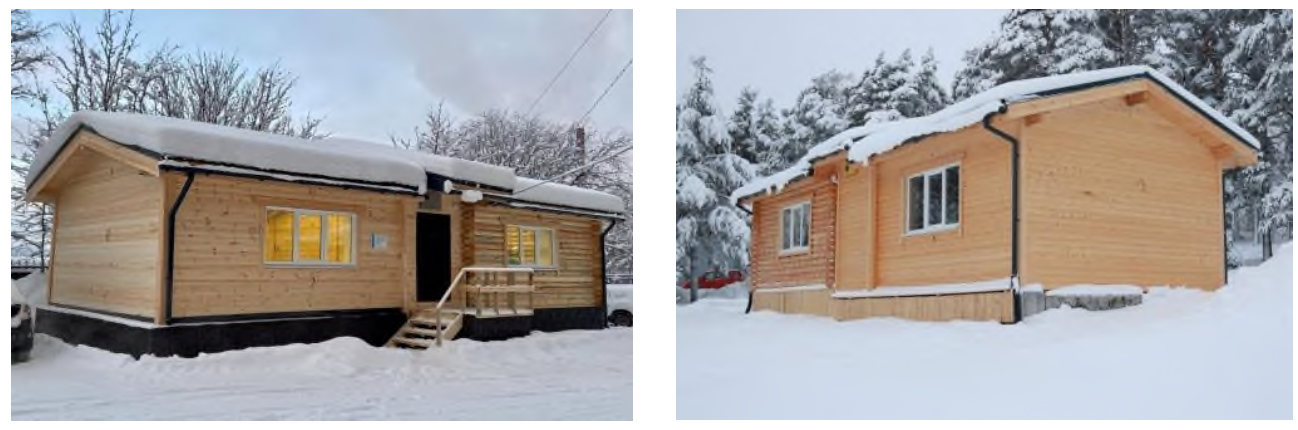

Fig. 1. Experimental buildings in Murmansk (left photo) and Petrozavodsk (right photo).

The internal volume of the building is represented by two rooms, mirror-symmetrical relative to the vestibule. The area and internal volume of the premises are the same. The structures of the lower floor and insulated roof are identical for the premises. The designs of the external walls are different: frame and in the form of a double log house, which consists of two layers of rounded logs with a space between them. Mineral wool slabs are the main insulation for frame walls, lower floors and roofs. Wood shavings and sawdust, which are waste of the production of rounded logs, are taken as the main insulation of the $\log$ part.

The north wall of the frame and log part of the building is divided into three sections. In each of the three sections, the main insulation material has been replaced with an alternative 
thermal insulation material. For the frame part the alternative materials are board materials based on linen fiber, seaweed and ecowool, which is a sprayed material based on cellulose; for the log part there is flax fiber based on board materials and an air gap.

The thickness of the thermal insulation layers was selected according to the climatic conditions of Murmansk. As a result of the choice a general energy efficiency class for the entire building was achieved - A (very high) for both regions [11]. Due to the fact that the model objects will be experimental sites for various studies, including those related to the processes of heat transfer in the building envelopes, thermal protection of low-rise wooden buildings, the primary research task after the completion of construction is to assess their performance of the thermal protection function.

\subsection{Normative research methods}

The initial assessment of the heating - performance of the walls is carried out by thermovision inspection of the experimental buildings. The method of heat monitoring is regulated by GOST R 54852-2011 "Method of thermovision control of enclosing structures thermal insulation quality". This normative document takes into account the main provisions of the European regional standard DIN EN 13187-1999 "Thermal performance of buildings - Qualitative detection of thermal irregularities in building envelopes - Infrared method" (ISO 6781: 1983, modified; German version EN 13187: 1998). The purpose of the survey is to establish thermally homogeneous zones and locations of heat-conducting inclusions and obtain thermographic data on the external and internal surfaces of enclosing structures in natural conditions. Thermal imaging is performed in two stages. The first stage is a general survey, which reveals the reference (problem) zones of the enclosing structures. The second stage is a more detailed surveying of previously planned nodal points and identified reference (problem) points. It is planned to use "Testo" thermal imagers for thermal imaging.

In addition to thermal imaging, it is necessary to measure the heat flux density in order to quantitatively assess the thermal characteristics of enclosing structures and assess their compliance with regulatory requirements. The method for measuring the density of heat flows is described in GOST 25380-2014 "Method of measuring density of heat flows passing through enclosing structures". This study is also carried out to determine the actual heat loss through external enclosing structures at control points. For the measurement, it is planned to use a device for measuring the density of heat fluxes passing through singlelayer and multilayer enclosing structures of buildings and structures, ITP-MG4.03 / 3 (1) "Potok".

The third normative method is to determine the actual thermophysical properties of building materials in accordance with GOST 7076-99 "Method of determination of steadystate thermal conductivity and thermal resistance". The method for determining the properties of materials in a stationary thermal regime is chosen as the most accurate. Determination of the actual thermal conductivity and thermal resistance of the applied structural and heat-insulating materials is necessary to clarify the adopted design solutions. The data obtained as a result of laboratory studies are necessary for further calculations to build a theoretical model of the temperature field distribution in the structure of the enclosing structure, to calculate the reduced resistance and further determine the energy efficiency class under operating conditions.

\subsection{Monitoring system (experimental research method)}

The experimental buildings are equipped with a monitoring system for the parameters of the internal microclimate [15-16], enclosing structures and the environment. During 
construction, sensors were located into the layers of the enclosing structures to record temperature and humidity. The sensors are located in 25 nodal (measuring) points, which are situated in key places of the enclosing structure. The following key points are: in the structures of the insulated pitched roof and lower floor, in the walls of the building - on homogeneous (by the type of insulation) sections on different levels of the wall, in the locations of various types of heat-insulating materials, as well as in the corners and near window openings (Figure 2).

The sensor system includes two subsystems. The reference system is implemented on the basis of the industrial sensor programmable controller OWEN SPK107, as well as humidity and temperature sensors PVT100-N5.2.I.2. The sensors of the reference system are located at all control points in one arbitrarily chosen structure layer. The multichannel measuring subsystem is based on ESP8266 NodeMCU V3 microcontrollers and GYSHT31-D digital temperature and relative humidity sensors. The sensors of the measuring system are installed in all the layers of heterogeneous structures at all 25 nodal points.

Measurement of temperature and humidity in the layers of the structure inside the building, as well as the parameters of the external environment by means of the implemented monitoring system, will ensure the registration of values in real time under operating conditions and build a graphical distribution of temperature fields in the structure of the wall. Within the framework of this study, the measurement technique using the implemented monitoring system is considered as experimental. 


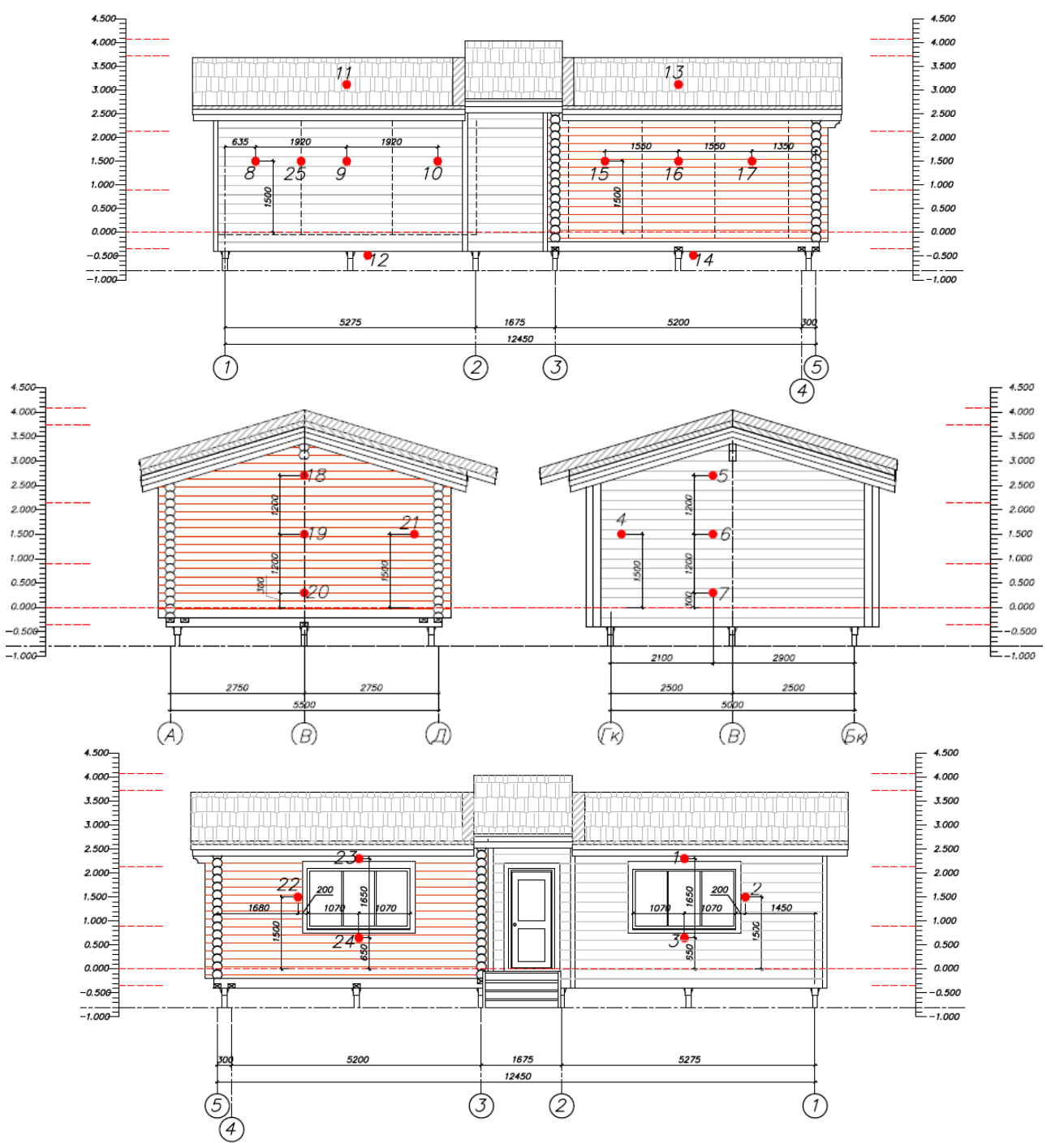

Fig. 2. Arrangement of points (nodes) of measurement.

\section{Results}

A comprehensive study of the energy efficiency of experimental buildings consists of three stages. The structural and logical diagram of the study at the first stage is shown in Figure 3. The stage under consideration refers to the study of the thermophysical properties of the enclosing structures of the walls. The time period for the implementation of the first stage is January 2021 - March 2021.

The main purposes of this stage of the study are the following:

1. Conducting a thermal imaging survey of experimental objects to control the general current state of enclosing structures in accordance with the National Standard of the Russian Federation GOST R 54852-2011.

1.1 General thermal imaging survey of the experimental building.

1.2 Detailed survey of control points, identification of problem areas. 
2. Measurement of heat flux density at control points of enclosing structures of experimental buildings in accordance with Interstate Standard GOST 25380-2014.

3. Clarification of the actual indicators of thermal conductivity of materials - thermal resistance of the material of each layers of the enclosing structure (in accordance with Interstate Standard GOST 7076-99) used in the construction of experimental facilities and correction of the design model (if necessary).

4. Monitoring of temperature and humidity in the layers of non-uniform enclosing structures (in accordance with the experimental method).

The study under consideration has been carried out in test mode since November 2020. At the step of the stage under consideration, a stationary mode of operation of objects is provided for at a constant internal temperature and air humidity. Stationary conditions for conducting experiments are achieved by ensuring the temperature and humidity of the air inside the room at a level corresponding to the sanitary and epidemiological requirements the air temperature is $22-24{ }^{\circ} \mathrm{C}$, and the air humidity is $40-60 \%$. Environmental parameters (air temperature, humidity, wind speed and direction) during the study are variable components. The preservation of the normative parameters of the internal climate of premises is ensured by the automated regulation of the operation of the heat supply system of the building [13], depending on the parameters of the external environment. The external conditions for the climatic regions of Petrozavodsk and Murmansk are naturally different. In this regard, the periods of the experiments are selected in the most severe winter conditions to ensure the specified conditions of the internal microclimate of the building. To conduct experiments on the territories under consideration, the days are selected with the same weather conditions and with the lowest ambient temperature. This is necessary for the subsequent comparison of the results. 


\section{Comprehensive assessment of the energy efficiency of enclosing structures}

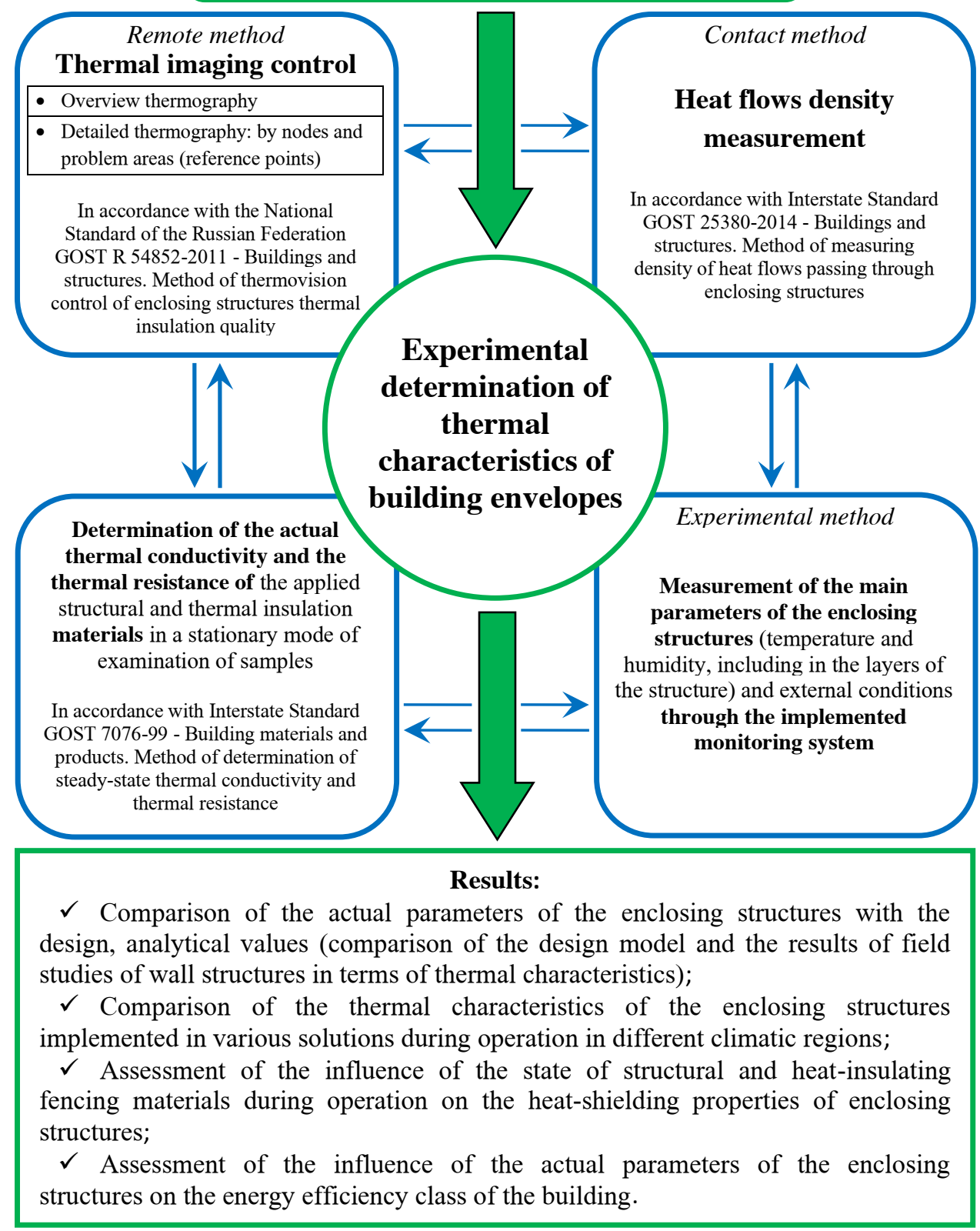

Fig. 1. Structural and logical diagram of the study in a stationary mode of the building microclimate (first stage). 


\section{Discussion}

\subsection{Comprehensive assessment of the energy efficiency of enclosing structures}

A comprehensive assessment of the energy efficiency of building envelopes within the framework of the proposed research program is implemented through a series of experiments described above with two identical experimental buildings operated in different climatic conditions. An integrated approach to solving the tasks of the first stage provides an opportunity to assess the comparability of the results obtained by different methods. The data obtained as a result of the planned research of the stage under consideration will be used to implement further research tasks, which include the following: - Comparison of the actual parameters of the enclosing structures with the design, analytical values (comparison of the design model and the results of field studies of wall structures in terms of thermal characteristics);

- Comparison of heat engineering characteristics of enclosing structures, implemented in different solutions, during the operation in different climatic regions;

- Simulation of the process of heat transfer through building envelope structures;

- Assessment of the influence of the state of structural and heat-insulating materials of fences during operation on the heat-shielding properties of enclosing structures;

- Assessment of the influence of the actual parameters of the enclosing structures on the energy efficiency class of the building (evaluation of experimental data regarding the influence of the enclosing structures on the energy efficiency class of the building within the framework of the previously formulated hypothesis [11]);

- Theoretical and experimental study of the heat-shielding characteristics of wooden lowrise buildings in the conditions of the northern territories.

\section{Conclusions}

1. In order to ensure sustainable development through the rational use of energy resources and local materials (wood), the expediency of performing the above set of studies on the energy efficiency of enclosing structures in regions with a cold climate has been substantiated [10].

2. Two identical objects built in 2020 on the territories of Murmansk and Petrozavodsk will be used as an experimental base for carrying out a complex of studies [12-14].

3. The choice of engineering systems for an experimental low-rise wooden building for two regions with a cold climate (Murmansk region and the Republic of Karelia) has been substantiated [13].

4. A system for monitoring the air temperature and humidity of the experimental frame wooden house has been developed, implemented and is being functioned in test mode [15-16].

5. The next tasks of continuation of the presented research using the constructed experimental objects in Murmansk and Petrozavodsk are determined.

\section{References}

1. A. Kosonen, A. Keskisaari, Zero-energy log house - Future concept for an energy efficient building in the Nordic conditions, Energy and Buildings, 228, 110449 (2020) 
2. Ch. Boardman, S. Glass, Improving the Accuracy of a Hygrothermal Model for WoodFrame Walls: A Cold-Climate Study. Buildings, 10(12), 236 (2020)

3. B. R. Sørensen, R. Riise, Some Issues of Energy Performance and Management of Residential Buildings in Norway and North-west Russia. 2014 International Conference on Mechanics and Civil Engineering (icmce-14), 1052-1057 (2014)

4. Xu. Yizhong, M. Mustafa, R. K. Calay, B. R. Sørensen, Numerical study on the ventilation performance of a livestock house built in porous panels in Cold Regions. IOP Conference Series: Materials Science and Engineering, 700(1), 012026 (2019)

5. A. Nadeem, Y. Abzhanov, S. Tokbolat, M. Mustafa, B. R. Sørensen, The Impacts of Climate Zone, Wall Insulation, and Window Types on Building Energy Performance. Joint International Conference on Design and Construction of Smart City Components, 270-277 (Springer, Cham, 2019)

6. Z. Pásztory, G. A. Gorbacheva, V. G. Sanaev, Z. Börcsök, Heating energy demand savings of typical log home in different regions of Russia. Forestry Bulletin, 23(5), 101-107 (2019)

7. T. A. Golova, A. P. Denisova, Energy efficiency of the Rural Wall multi-layer structure in low-rise building design. Magazine of Civil Engineering, 52(8), 9-19 (2014)

8. M. I. Zaitseva, S. N. Koshelev, A. A. Kuzmenkov, An integrated approach to the construction of buildings with reduced energy consumption for heating. Resources and Technology, 13(3) (2016)

9. A. Kuzmenkov, E. Tikhonov, G. Kolesnikov, Thermal Bridges in Wall Panels of Wooden Frame Houses. EECE 2019. Lecture Notes in Civil Engineering, 70, 329-336 (Springer, Cham, 2020)

10. S. E. Sveen, Energy efficiency wooden module house for North-West Russia - project period 2003-2007. Wooden low-rise housing construction: economy, architecture and resource-saving technologies, 78-82 (2019)

11. S. Y. Buryachenko, I. M. Karachentseva, Z. A. Voronin, A. A.Kuzmenkov, The influence of enclosing structures of walls on the energy efficiency of a wooden building (on the example of the international project KO 1089 "Green Arctic Building”). IOP Conference Series: Earth and Environmental Science, 539(1), 012024 (2020)

12. A. A. Kuzmenkov, I. M. Karachentseva, S. Y. Buryachenko, Justification of wall material choice of the experimental building for implementation of the international project KO 1089 "Green Arctic Building" - GraB. Wooden low-rise housing: economics, architecture and resource-saving technologies, 106-111 (2019)

13. I. M. Karachentseva, A. A.Kuzmenkov, Justification of the choice of engineering support systems for an experimental low-rise wooden building. Resource-saving technologies, materials and structures, 36-43 (2020)

14. A. A. Kuzmenkov, I. M. Karachentseva, A. V. Derbenev, Construction of an experimental wooden low-rise building. Wooden low-rise housing: economics, architecture and resource-saving technologies, 32-50 (2020)

15. D. A. Kuvshinov, A. A. Kuzmenkov, Air temperature and humidity monitoring system for an experimental timber frame house. In European research, 7, 36-40 (2020)

16. D. A. Kuvshinov, Testing the air temperature and relative humidity monitoring system in the experimental wooden house. Wooden low-rise housing: economics, architecture and resource-saving technologies, 51-58 (2020) 